\title{
Lung volumes and lung volume recruitment in ARDS: a comparison between supine and prone position
}

Hernan Aguirre-Bermeo, Marta Turella, Maddalena Bitondo, Juan Grandjean, Stefano Italiano, Olimpia Festa, Indalecio Morán and Jordi Mancebo*

\begin{abstract}
Background: The use of positive end-expiratory pressure (PEEP) and prone position (PP) is common in the management of severe acute respiratory distress syndrome patients (ARDS). We conducted this study to analyze the variation in lung volumes and PEEP-induced lung volume recruitment with the change from supine position (SP) to PP in ARDS patients.

Methods: The investigation was conducted in a multidisciplinary intensive care unit. Patients who met the clinical criteria of the Berlin definition for ARDS were included. The responsible physician set basal PEEP. To avoid hypoxemia, $\mathrm{FiO}_{2}$ was increased to $0.81 \mathrm{~h}$ before starting the protocol. End-expiratory lung volume (EELV) and functional residual capacity (FRC) were measured using the nitrogen washout/washin technique. After the procedures in SP, the patients were turned to PP and $1 \mathrm{~h}$ later the same procedures were made in PP.

Results: Twenty-three patients were included in the study, and twenty were analyzed. The change from SP to PP significantly increased FRC (from $965 \pm 397$ to $1140 \pm 490 \mathrm{ml}, p=0.008$ ) and EELV (from $1566 \pm 476$ to $1832 \pm 719 \mathrm{ml}, p=0.008)$, but PEEP-induced lung volume recruitment did not significantly change $(269 \pm 186 \mathrm{ml}$ in $\mathrm{SP}$ to $324 \pm 188 \mathrm{ml}$ in PP, $p=0.263)$. Dynamic strain at PEEP decreased with the change from SP to PP $(0.38 \pm 0.14$ to $0.33 \pm 0.13, p=0.040)$.
\end{abstract}

Conclusions: As compared to supine, prone position increases resting lung volumes and decreases dynamic lung strain.

Keywords: ARDS, Lung volumes, Lung strain, Prone, PEEP recruitment, Mechanical ventilation

\section{Background}

Acute respiratory distress syndrome (ARDS) is a permeability pulmonary edema, characterized by hypoxemia and a decrease in lung volumes and respiratory system compliance $[1,2]$. In patients with ARDS, prone position (PP) produces a more homogeneous distribution of the inspired gas [3] and a better matching between ventilation and perfusion, thereby improving arterial oxygenation [3-5]. Positive end-expiratory pressure (PEEP)

\footnotetext{
*Correspondence: jmancebo@santpau.cat

Servei de Medicina Intensiva, Hospital de la Santa Creu i Sant Pau, Universitat Autònoma de Barcelona (UAB), Sant Quintí, 89, 08041 Barcelona, Spain
}

and PP have also shown to decrease the percentage of non-aerated and poorly aerated lung tissue and attenuate the regional recruitment-derecruitment phenomena [5-7]. In selected ARDS patients, PP has been proposed to further improve the outcomes [8]. The benefit on survival of PP is not related only to the improvement in gas exchange $[9,10]$, and the protective effect on ventilatorinduced lung injury $[3,9,11,12]$ could also play a role. As compared to supine position (SP), the PP reduces the steep transpulmonary pressure gradient across the vertical axis of the lung, leading to a more homogeneous distribution of pulmonary stress and strain $[2,3,13]$.

However, data analyzing the variation in lung volumes with the change from SP to PP in ARDS patients 
are scarce and conflicting [4, 14-17]. We hypothesized that in ARDS patients, PP increases lung volumes (i.e., functional residual capacity and end-expiratory lung volume) and might decrease lung strain $[16,18]$. Because the measurement of functional residual capacity (FRC) requires to be made at zero end-expiratory pressure (ZEEP), our study included a lung derecruitment maneuver from baseline PEEP to zero PEEP [19-21] subsequently followed by the reinstitution of the basal PEEP level. These allowed to analyze the variation in lung volumes and to estimate lung volume recruitment and lung strain in both supine and prone positions in patients with ARDS.

\section{Methods}

The study was performed in the Intensive Care Department at Hospital de la Santa Creu i Sant Pau, Barcelona (Spain). This study was conducted in accordance with the amended Declaration of Helsinki.

\section{Patients}

Patients were considered eligible for the study if they met the Berlin definition criteria for ARDS [22] and had an indication for PP in accordance with our department's protocol $\left(\mathrm{PaO}_{2} / \mathrm{FiO}_{2}\right.$ ratio of $<150 \mathrm{~mm} \mathrm{Hg}$ and $\mathrm{FiO}_{2}$ of $\geq 0.6$ with PEEP of at least $5 \mathrm{~cm} \mathrm{H}_{2} \mathrm{O}$ ). We recommend to use protective ventilation with individualized low tidal volume $(\mathrm{Vt})$ and moderate PEEP levels. Essentially, PEEP is titrated according to the gas exchange $\left(\right.$ Sat $\mathrm{O}_{2}$, measured by pulse oxymeter, around 95\%) with endinspiratory plateau airway pressure (Pplat) not higher than $28 \mathrm{~cm} \mathrm{H}_{2} \mathrm{O}$ and without hemodynamic instability (mean arterial pressure above $65 \mathrm{~mm} \mathrm{Hg}$ and no need for fluid replacement). Our detailed ventilatory strategy is included in Additional file 1. Hence, all our patients had been turned in PP before inclusion in the study. To be included, patients had to present an improvement in gas exchange $\left(\mathrm{FiO}_{2} \leq 0.6\right.$ and $\left.\mathrm{PEEP} \leq 12 \mathrm{~cm} \mathrm{H}_{2} \mathrm{O}\right)$ in $\mathrm{SP}$ in order to avoid severe hypoxemia because of the derecruitment (induced by PEEP withdrawal and ventilation at ZEEP) during the measurement of FRC. Exclusion criteria were: age $<18$ years, tracheostomy, pregnancy, major trauma, barotrauma (presence of extra-alveolar air during mechanical ventilation as assessed by daily chest $\mathrm{X}$ ray) and hemodynamic instability (systolic blood pressure $<80$ or $>160 \mathrm{~mm} \mathrm{Hg}$, heart rate $<50 \mathrm{bpm}$ or $>130 \mathrm{bpm}$ or changes in $\pm 20 \%$ from baseline).

All patients were under continuous sedation and analgesia with intravenous perfusion of midazolam and/ or propofol and opioids. During the study period, all patients received neuromuscular blocking agents.

\section{Protocol}

The following data were collected: age, height, simplified acute physiology score III at admission, ARDS etiology, days of mechanical ventilation, intensive care unit outcomes, respiratory rate, Vt, PEEP, peak airway pressure, Pplat and arterial blood gases. Respiratory variables were recorded directly from the ventilator.

All patients were ventilated in volume control ventilation using the same ventilator model (Engström Carestation ICU ventilator, General Electric, Madison, WI, USA).

To avoid hypoxemia, defined as oxygen saturation $\leq 88 \%$ measured through pulse oximetry, we increased the $\mathrm{FiO}_{2}$ to $0.81 \mathrm{~h}$ before starting the protocol.

\section{Measurements}

Baseline ventilatory and hemodynamic parameters were collected before the protocol to measure lung volumes. The same procedures were carried out in SP and PP and are outlined below (see also Fig. 1):

1. Measurement of end-expiratory lung volume (EELV): EELV is the resting end-expiratory lung volume measured at baseline PEEP.

2. Removal of PEEP and continuation of mechanical ventilation at ZEEP. This derecruitment maneuver

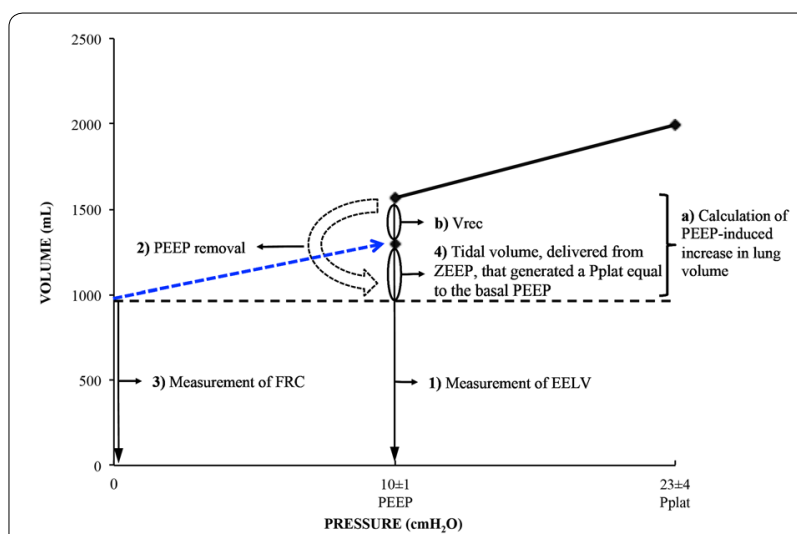

Fig. 1 Lung volumes, measurements and calculations made in the study. The same procedures were carried out in supine and prone positions as follows: (1) measurement of end-expiratory lung volume (EELV): EELV is defined as the resting end-expiratory lung volume at PEEP. (2) Removal of PEEP and continuation of mechanical ventilation at zero end-expiratory pressure (ZEEP). (3) Measurement of functional residual capacity (FRC): $F R C$ is defined as the resting lung volume at ZEEP. (4) Measurement of the tidal volume, delivered from ZEEP, that generated a Pplat equal to the basal PEEP. The same calculations were carried out in supine and prone positions as follows: (a) calculation of PEEP-induced increase in lung volume $=$ EELV minus FRC. (b) Calculation of PEEP-induced lung volume recruitment $(V r e c)=P E E P-$ induced increase in lung volume minus the $\mathrm{Vt}$, delivered from ZEEP, that generated a Pplat equal to the basal PEEP. Blue line represents the compliance at ZEEP 
is mandatory to conduct the following step 3 , and it is the reason to increase the $\mathrm{FiO}_{2}$ to 0.8 immediately before starting the protocol (i.e., to avoid hypoxemia).

3. Measurement of functional residual capacity (FRC): FRC is the resting lung volume measured at ZEEP.

4. Measurement of the Vt, delivered from ZEEP, that generated a Pplat equal to the basal PEEP. This step (see Fig. 1) is mandatory to allow a proper estimation of the PEEP-induced lung volume recruitment [19, 20, 23-25].

Once step 4 was completed, the same PEEP that was used at baseline was resumed.

Measurements at ZEEP (FRC and Vt delivered from ZEEP, that generated a Pplat equal to the basal PEEP) included a lung derecruitment maneuver (PEEP removal) that can produce hypoxemia. For the purpose of our investigation, we defined hypoxemia as oxygen saturation $\leq 88 \%$ measured through pulse oximetry.

The safety limits and contraindications to remove PEEP were:

1. PEEP removal was contraindicated if $\mathrm{FiO}_{2}>0.6$ and PEEP > $12 \mathrm{~cm} \mathrm{H}_{2} \mathrm{O}$.

2. We increased the $\mathrm{FiO}_{2}$ to $0.81 \mathrm{~h}$ before starting the protocol in order to avoid hypoxemia during PEEP removal.

3. If a patient presented with hypoxemia at any time during the protocol (saturation $\leq 88 \%$ measured through pulse oximetry), the measurements were aborted and the patient was excluded.

Lung volumes (EELV and FRC) were measured twice using the nitrogen washout/washin technique available in Engström Carestation ICU ventilator as previously described [24, 26]. Washout/washin technique is a multiple breath maneuver that with a modification of 0.1 in $\mathrm{FiO}_{2}$ calculates the residual nitrogen in the lung (assuming there is not exchange of nitrogen) by continuous measurements of oxygen and carbon dioxide. The ventilator was carefully calibrated before the measurements according to the manufacturer's specifications. We obtained four values for each lung volume. The mean of the four values was used. As previously suggested [27], patients were excluded if the differences between the four values were more than 20\% (cutoff determined by the manufacturer).

After the procedures in SP, the patients were turned to $\mathrm{PP}$ and $1 \mathrm{~h}$ later the same procedures (from 1 to 4 above) were made in PP. This time span was based in previous data showing that after $1 \mathrm{~h}$ in PP gas exchange is stable in the majority of patients $[28,29]$. If a patient presented with hypoxemia (oxygen saturation $\leq 88 \%$ ) at any time during the protocol, the measurements were aborted and the patient was excluded.

The normal reference values for FRC (liters) in the SP were calculated according to the equation described by Ibáñez and Raurich [30], as follows: $5.48 \times$ height-7.05 for men and $1.39 \times$ height -0.424 for women; height units are in meters. Compliance $\left(\mathrm{ml} / \mathrm{cm} \mathrm{H}_{2} \mathrm{O}\right)$ was calculated as Vt/(Pplat minus total PEEP), being total PEEP the sum of PEEP plus intrinsic PEEP. Predicted body weight was calculated as follows: $50+0.91$ (height-152.4) for men and $45.5+0.91$ (height-152.4) for women; height units are in centimeters. Driving airway pressure was calculated as the difference between Pplat and total PEEP [31].

\section{Calculation of lung volumes and strain}

(a) The PEEP-induced increase in lung volume was calculated as EELV minus FRC (see Fig. 1).

(b) PEEP-induced lung volume recruitment (Vrec) was calculated as PEEP-induced increase in lung volume minus the $\mathrm{Vt}$, delivered from $\mathrm{ZEEP}$, that generated a Pplat equal to the basal PEEP (see Fig. 1).

(c) Strain was calculated as previously described [24, 32, 33]:

1. Dynamic strain at $Z E E P=V t / F R C$.

2. Dynamic strain at PEEP $=\mathrm{Vt} /(\mathrm{FRC}+\mathrm{Vrec})$.

3. Static strain at PEEP $=(\mathrm{EELV}-\mathrm{FRC}) /$ (FRC + Vrec).

4. Global strain at PEEP = (static strain at PEEP + dynamic strain at $\mathrm{PEEP})=(\mathrm{EELV}-\mathrm{FRC}+\mathrm{Vt}) /(\mathrm{FRC}+\mathrm{Vrec})$.

\section{Statistical analysis}

Data are expressed as mean \pm SD. We used Wilcoxon test to compare variables between supine and prone positions and $U$ the Mann-Whiney test to compare early and non-early ARDS patients. A $p$ value $<0.05$ was considered statistically significant. The SPSS ${ }^{\circledR}$ Statistics (version 20.0, Chicago, IL, USA) statistical software was used for statistical analysis.

\section{Results}

The study was conducted from July 2010 to December 2013. Twenty-three patients were included in the study, and twenty were analyzed. One patient was excluded because of hypoxemia during the FRC measurement, and two were excluded because of a technical problem. (The differences between FRC measurements were > 20\%.)

Table 1 summarizes the patients' main characteristics at baseline. The mean age of patients was $58 \pm 18$ years. The main causes of ARDS were pneumonia $(n=11)$ and septic shock $(n=4)$. The study was performed $4 \pm 3$ days 


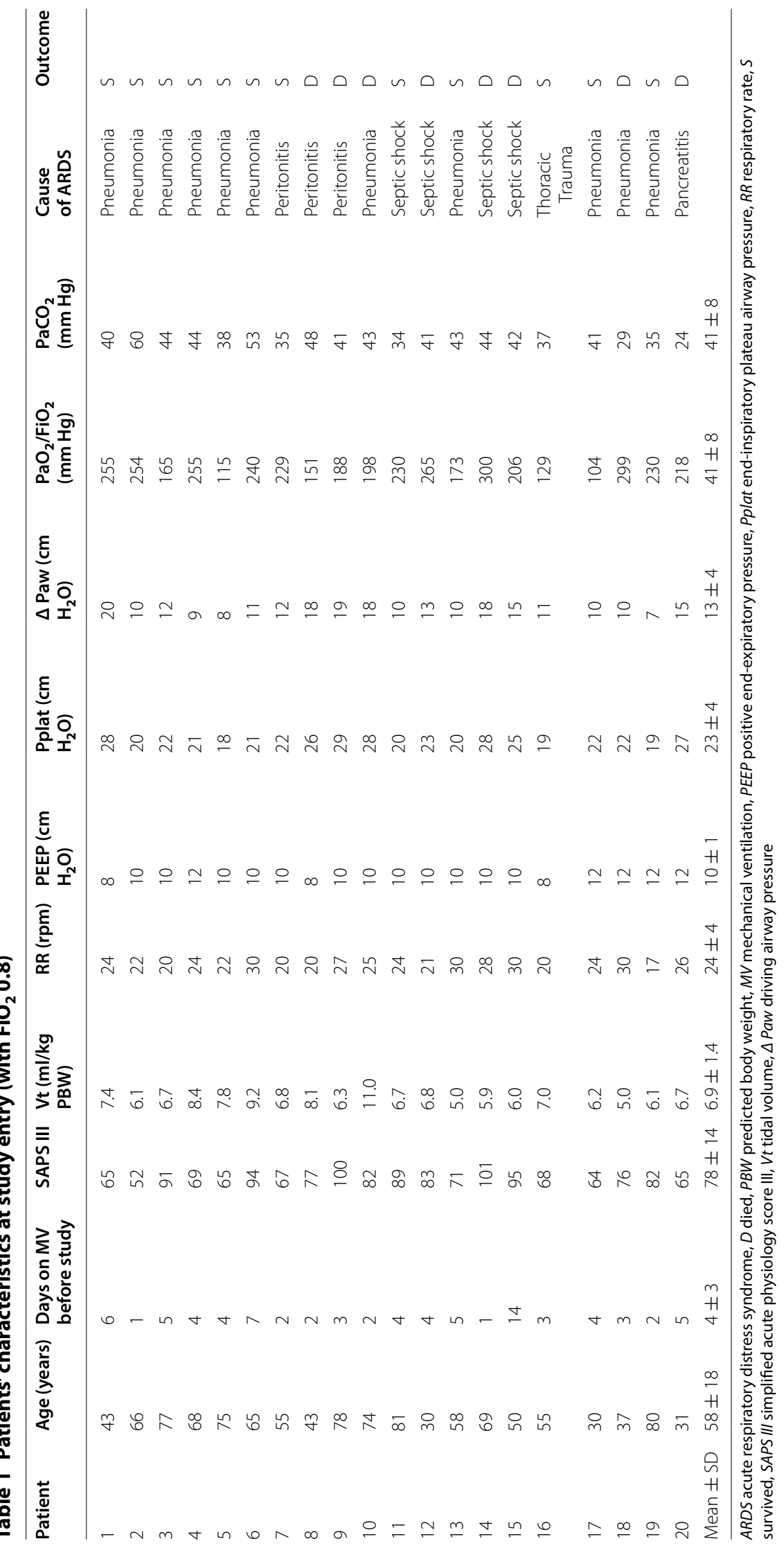


after starting mechanical ventilation. At baseline, mean $\mathrm{Vt}$ was $6.9 \pm 1.4 \mathrm{ml} / \mathrm{kg}$ of predicted body weight and mean PEEP was $10 \pm 1 \mathrm{~cm} \mathrm{H}_{2} \mathrm{O}$.

After assuming the PP, the $\mathrm{PaO}_{2} / \mathrm{FiO}_{2}$ ratio increased significantly, from $210 \pm 57 \mathrm{~mm} \mathrm{Hg}$ in supine to $281 \pm 109 \mathrm{~mm} \mathrm{Hg}$ in prone $(p=0.008)$ (Table 2).

The mean FRC in SP was significantly lower than its reference value in healthy normal subjects $(965 \pm 397$ vs. $2424 \pm 459 \mathrm{ml}, p \leq 0.001$ ). The change from SP to PP significantly increased both FRC (from $965 \pm 397$ to $1140 \pm 490 \mathrm{ml}, p=0.008$ ) and EELV (from $1566 \pm 476$ to $1832 \pm 719 \mathrm{ml}, p=0.008$ ) (Figs. 2, 3).

We did not calculate Vrec and derived parameters in four patients because the tidal volume delivered from ZEEP, that generated a Pplat equal to the basal PEEP, was not measured in accordance to the protocol. Vrec $(\mathrm{n}=16)$ did not significantly vary with the change of position $(269 \pm 186 \mathrm{ml}$ in SP to $324 \pm 188 \mathrm{ml}$ in PP, $p=0.263$ ) (Fig. 2).

We found a significant decrease in the dynamic strain at PEEP with the change from SP to PP from $0.38 \pm 0.14$ to $0.33 \pm 0.13(p=0.040)$ (Fig. 4). The dynamic strain at ZEEP also decreased, from $0.52 \pm 0.23$ in SP to $0.44 \pm 0.18$ in PP $(p=0.047)$. The remaining variables did not change significantly between supine and prone positions (Table 2) (Additional file 2: Table S1).

In the whole population, the driving pressure in the non-survivor group $(n=8)$ was significantly higher than in the survivor group $(n=12)$ in both SP $(16 \pm 3 \mathrm{~cm}$ $\mathrm{H}_{2} \mathrm{O}$ vs. $11 \pm 3 \mathrm{~cm} \mathrm{H}_{2} \mathrm{O}$, respectively, $\left.p=0.003\right)$ and in $\mathrm{PP}\left(15 \pm 3 \mathrm{~cm} \mathrm{H}_{2} \mathrm{O}\right.$ vs. $11 \pm 3 \mathrm{~cm} \mathrm{H}_{2} \mathrm{O}$, respectively, $p=0.005$ ). Additional data are also shown (Additional file 2: Table S2).

\section{Discussion}

The main findings in this study were that: (1) Prone position significantly increased lung volumes; (2) dynamic strain decreased significantly in prone position compared to supine position; and (3) the change of position from supine to prone did not modify the calculated PEEPinduced lung volume recruitment.

\section{Prone position, oxygenation and lung volumes}

In ARDS patients, lung volumes at ZEEP (FRC) and at PEEP (EELV) are typically decreased [18]. Two previous studies have shown that PP significantly increases FRC in ARDS patients $[15,16]$. Nevertheless, data about the changes in EELV with the change from SP to PP in ARDS patients are not consistent. Four previous studies have shown that PP increases EELV in ARDS patients as compared to SP [14-17], but another study [4] found that the change of EELV from SP to PP was not significant. These contradictory findings might be explained by differences in lung recruitability, distribution and extension of lung volume alterations, differences in chest wall compliance, the influence of abdominal weight and heart compression, the inclination from the horizontal plane and the use or not of ventral supports [3, 9, 34, 35].

In the present study, we found a $40 \%$ decrease in FRC as compared to its reference value in SP, confirming

Table 2 Main characteristics of all patients in each position

\begin{tabular}{|c|c|c|c|}
\hline Variable & $\begin{array}{l}\text { Supine } \\
n=20\end{array}$ & $\begin{array}{l}\text { Prone } \\
n=20\end{array}$ & $p$ \\
\hline $\mathrm{PaO}_{2} / \mathrm{FiO}_{2}(\mathrm{~mm} \mathrm{Hg})$ & $210 \pm 57$ & $281 \pm 109$ & 0.021 \\
\hline $\mathrm{PaCO}_{2}(\mathrm{~mm} \mathrm{Hg})$ & $41 \pm 8$ & $42 \pm 9$ & 0.400 \\
\hline Peak airway pressure $\left(\mathrm{cm} \mathrm{H}_{2} \mathrm{O}\right)$ & $41 \pm 7$ & $41 \pm 6$ & 0.284 \\
\hline Pplat $\left(\mathrm{cm} \mathrm{H}_{2} \mathrm{O}\right)$ & $23 \pm 4$ & $23 \pm 4$ & 0.446 \\
\hline Compliance $\left(\mathrm{ml} / \mathrm{cm} \mathrm{H}_{2} \mathrm{O}\right)$ & $36 \pm 11$ & $37 \pm 10$ & 0.594 \\
\hline$\triangle \operatorname{Paw}\left(\mathrm{cm} \mathrm{H}_{2} \mathrm{O}\right)$ & $13 \pm 4$ & $12 \pm 4$ & 0.446 \\
\hline $\mathrm{FRC}(\mathrm{ml})$ & $965 \pm 397$ & $1140 \pm 490$ & 0.021 \\
\hline EELV $(m l)$ & $1566 \pm 476$ & $1832 \pm 719$ & 0.009 \\
\hline Vt delivered from ZEEP, that generated a Pplat equal to basal PEEP $[\mathrm{ml}(n=16)]$ & $333 \pm 105$ & $360 \pm 127$ & 0.073 \\
\hline $\operatorname{Vrec}[\mathrm{ml}(n=16)]$ & $269 \pm 186$ & $324 \pm 188$ & 0.501 \\
\hline Dynamic strain at ZEEP & $0.52 \pm 0.23$ & $0.44 \pm 0.18$ & 0.040 \\
\hline Dynamic strain at PEEP $(n=16)$ & $0.38 \pm 0.14$ & $0.33 \pm 0.13$ & 0.020 \\
\hline Static strain at PEEP $(n=16)$ & $0.51 \pm 0.16$ & $0.48 \pm 0.13$ & 0.438 \\
\hline Global strain at PEEP $(n=16)$ & $0.89 \pm 0.24$ & $0.81 \pm 0.18$ & 0.121 \\
\hline
\end{tabular}

Data are presented as mean \pm SD. Dynamic strain at ZEEP $=$ Vt $/ F R C ;$ dynamic strain at PEEP $=\mathrm{Vt} /(\mathrm{FRC}+\mathrm{Vrec}) ;$ static strain at PEEP $=(\mathrm{EELV}-\mathrm{FRC}) /(\mathrm{FRC}+\mathrm{Vrec}) ; \mathrm{global}$ strain at $\mathrm{PEEP}=(\mathrm{EELV}-\mathrm{FRC}+\mathrm{Vt}) /(\mathrm{FRC}+\mathrm{Vrec})$

EELV end-expiratory lung volume, FRC functional residual capacity, PEEP positive end-expiratory pressure, Pplat end-inspiratory plateau airway pressure, Vrec PEEPinduced lung volume recruitment, $V t$ tidal volume, $\triangle P a w$ driving airway pressure 


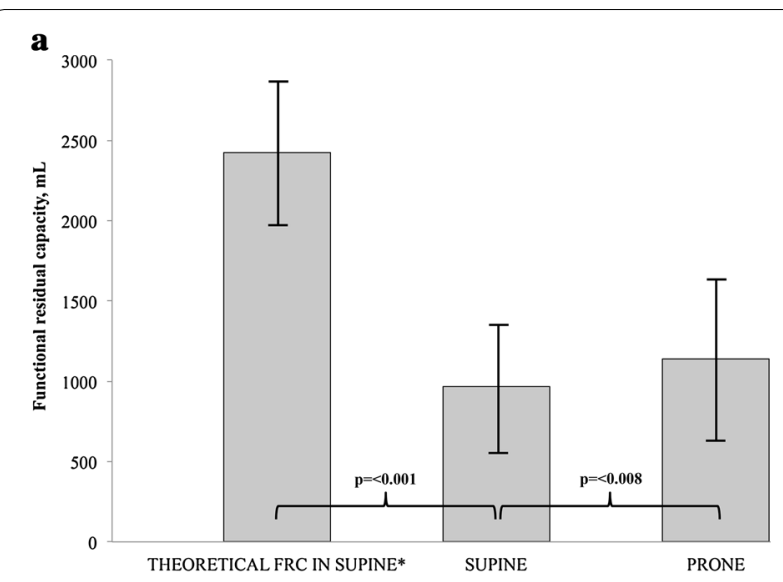

$$
\text { b }
$$

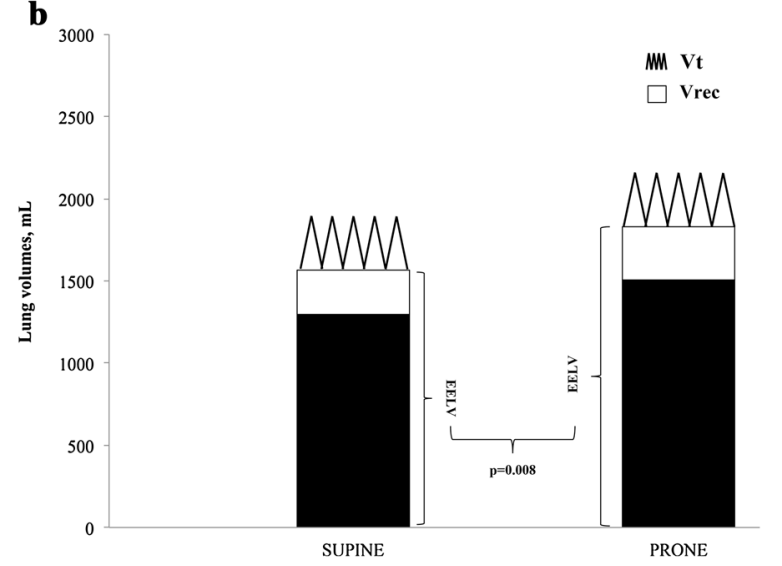

Fig. 2 Variation of lung volumes with the change of position. a Comparison of different values of functional residual capacity. b Comparison of EELV and Vrec in supine position and prone position. EELV, end-expiratory lung volume; Vrec, PEEP-induced lung volume recruitment; $\mathrm{Vt}$, tidal volume. Data are presented in mean $(\mathrm{ml})$ and SD. *According to the equation described by Ibañez and Raurich [30]

previous results [18]. We also observed that the FRC and EELV increased significantly with the change of position (18\% in FRC and $17 \%$ in EELV). Santini et al. [7] performed a study in animals with normal lungs, and they found a significant increase in FRC with the change from $\mathrm{SP}$ to PP. The increase in resting lung volume was mainly related to a redistribution of aeration: a minor decrease in non-aerated lung tissue (3\%), a major decrease in poorly aerated tissue $(17 \%)$ and a major increase $(20 \%)$ in wellaerated tissue. Since recruitment, as precisely measured by thoracic CT scan, refers to tissue recruitment (i.e., amount of non-inflated tissue that reinflates at a higher pressure), the decrease in poorly aerated tissue and the increase in well-aerated tissue (which contribute to the end-expiratory lung volume increase induced by PEEP) are thus considered as better gas distribution within the lung and not recruitment per se [36].

\section{Prone position and strain}

During passive mechanical ventilation, the force applied by the ventilator generates an internal tension in the fibers of the lung skeleton, called "stress," and the elongation of these fibers from their resting position is called "strain" [2]. High values of dynamic lung strain (lung deformation caused by Vt) and static lung strain (lung deformation caused by PEEP) are associated with ventilator-induced lung injury $[32,37]$.

In an animal model, Protti et al. [33] showed that for the same global strain, a large static strain is less harmful than a large dynamic strain. On the same vein, GonzálezLópez et al. [38] found that increased strain was associated with a proinflammatory lung response in patients with acute lung injury. Moreover, Bellani et al. [39] found in patients with acute lung injury that the intensity of metabolic activity (a surrogate of inflammation) detected by positron emission tomography was correlated with regional strain. Consequently, the significant decrease in dynamic strain in PP as compared to SP could be another mechanism of protection of PP against ventilatorinduced lung injury. Therefore, the measurement of lung volumes at bedside may be an important tool to deliver a more physiologically based ventilation and encourage physicians to increase the use of PP in moderately to severe ARDS patients [40].

\section{Prone position and PEEP-induced lung volume recruitment} It is still unclear whether the PEEP-induced alveolar recruitment varies with the change from SP to PP. In an experimental study in animals with lung injury, Richard et al. [5] analyzed the variation of alveolar recruitment at PEEP $10 \mathrm{~cm} \mathrm{H}_{2} \mathrm{O}$ in SP and PP by means of the positron emission tomography technique. They found that in PP, PEEP-induced alveolar recruitment was not higher than in SP. Interestingly, in this study, the authors observed a redistribution of densities in PP (recruitment in dorsal regions with derecruitment in ventral regions). Cornejo et al. [6] performed another study in ARDS patients to determine the effects of PEEP and PP on alveolar recruitment. Using the $\mathrm{CT}$ scan technique, they found that increasing PEEP from $5 \mathrm{~cm} \mathrm{H}_{2} \mathrm{O}$ to $15 \mathrm{~cm} \mathrm{H}_{2} \mathrm{O}$ significantly increased alveolar recruitment. However, the percentage of recruitment was similar in both positions (36\% in SP and 33\% in PP). Using a different methodology, the data from our study are consistent with these findings, indicating that the effects of PEEP on lung volume recruitment are similar in both positions (around 17\% of EELV).

A previous study by Grasso et al. [41] found that alveolar recruitment was higher in the early phase $(1 \pm 0.3$ days of mechanical ventilation) than in the late phase of ARDS, but a subsequent study by Gattinoni 


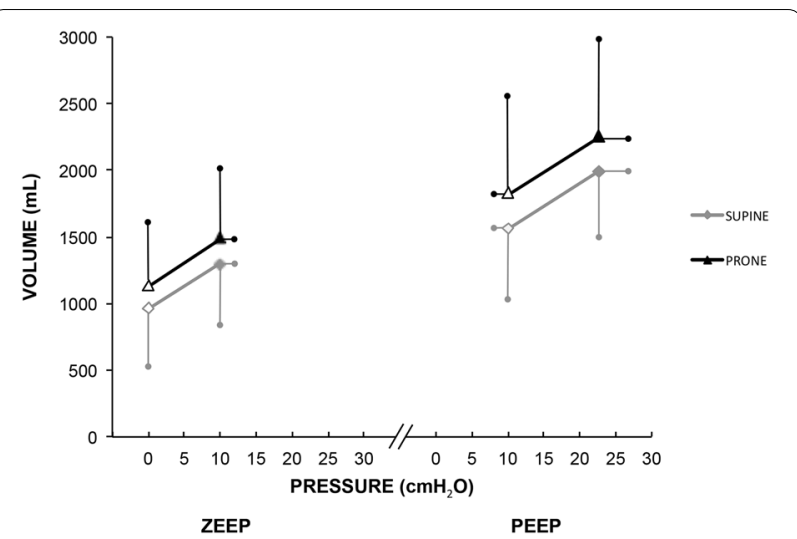

Fig. 3 Variation in lung volumes in supine and prone positions. Clear triangles and clear rhombus are the resting lung volumes at ZEEP and at PEEP. Dark triangles and dark rhombus represent end-inspiratory lung volumes and end-inspiratory lung pressure (Pplat) at ZEEP and at PEEP. PEEP, positive end-expiratory pressure; ZEEP, zero end-expiratory pressure. Data are shown as mean and SD

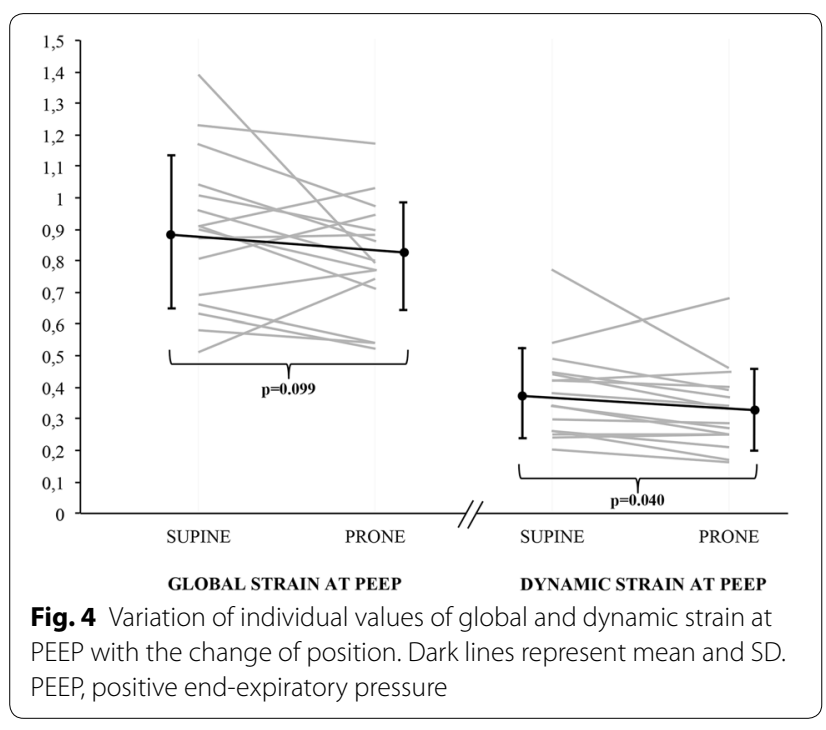

et al. [42] did not find the same results. In the study of Gattinoni et al. [42], they found that the number of days of mechanical ventilation before the study was similar in patients with a lower percentage of potentially recruitable lung and those with a higher percentage ( $5 \pm 6$ vs. $6 \pm 6$ days, respectively, $p=0.50)$. In our study when we classified ARDS patients in the early phase $(<72 \mathrm{~h})$ and in late phase (> $72 \mathrm{~h}$ ) (Additional file 2: Table S2), we observed results similar to those of Gattinoni et al. [42]: no statistical differences in lung volume recruitment between the early and late phase group were detected. In our study, however, in the early phase of
ARDS, lung volumes increased and strain decreased with the change from SP to PP, whereas in late phase ARDS we did not observe these findings (Additional file 2: Table S2). These differences could be related to the presence of some degree of hydrostatic pulmonary edema in the early phase of ARDS, and to the presence of fibrosis in the non-early phase of ARDS that predisposes to non-responsiveness to PP in terms of increasing in lung volumes and decreasing strain [43]. Our findings thus suggest that the survival benefit may, in part, be related to the early application of PP as it increases resting lung volumes and decreases lung strain compared to SP. It is also tempting to speculate that the lack of differences in Vrec between supine and prone, and the increase in overall lung volume in prone as compared to supine, can be explained by a decrease of poorly ventilated areas and an increase of well ventilated areas, which in turn might help to decrease lung inhomogeneity. It has been shown that the extent of lung inhomogeneities (as quantified by the amount of poorly ventilated tissue) is associated with worse outcomes in ARDS patients, possibly due to a mechanism of "stress raisers" [44].

\section{Limitations}

Like many physiological studies [4, 6, 14-17, 34], our study has a relatively low number of patients. Another limitation is that the measurement of FRC could be subject to the tolerance to PEEP removal and the $\mathrm{FiO}_{2}$ used. However, when the study was performed, all the patients met the criteria for mild-moderate ARDS according to the Berlin definition [22]. We did not perform a multislice spiral lung computed tomography to measure the quantitative changes in alveolar aeration induced by PEEP and PP. Other measurements of lung mechanics (i.e., esophageal pressure and derived variables) and lung biomarkers could help to further explain the effects of PEEP and positioning in ARDS patients, but we did not do these because of lack of adequate equipment at the time of the study. Finally, to confirm the changes, it might have been useful to return the patients from PP to SP and to repeat the same procedures and measurements; this was not done, however, because most patients remained in the PP as per clinical decision after the study had been completed.

\section{Conclusions}

As compared to supine, prone position increases resting lung volumes without significantly changing the recruited volume kept by PEEP. Moreover, the change of position from supine to prone decreases dynamic lung strain. These findings help to better understand the beneficial effects of prone position in ARDS patients. 


\section{Additional files}

Additional file 1. The institutional protocol.

Additional file 2. Additional patient per patient physiological data in supine and prone position (Table S1 and Table S2).

\section{Abbreviations}

ARDS: acute respiratory distress syndrome; EELV: end-expiratory lung volume; FRC: functional residual capacity; PEEP: positive end-expiratory pressure; PP: prone position; Pplat: end-inspiratory plateau airway pressure; SP: supine position; Vrec: PEEP-induced lung volume recruitment; Vt: tidal volume; ZEEP: zero end-expiratory pressure.

\section{Authors' contributions}

All authors participated in the study design, data collection and analysis, manuscript writing and final approval. All authors read and approved the final manuscript.

\section{Competing interests}

General Electric provided the equipment (Engström Carestation ICU ventilator) to conduct this research.

\section{Acknowledgements}

Not applicable.

\section{Availability of data and materials \\ Not applicable.}

\section{Consent for publication}

The patients' relatives gave written informed consent to participate and publish.

\section{Ethics approval and consent to participate}

The ethics committee of Hospital de la Santa Creu i Sant Pau approved the study (Reference 68/2010).

\section{Publisher's Note}

Springer Nature remains neutral with regard to jurisdictional claims in published maps and institutional affiliations.

\section{Received: 2 November 2017 Accepted: 8 February 2018}

Published online: 14 February 2018

\section{References}

1. Ware LB, Matthay MA. The acute respiratory distress syndrome. N Engl J Med. 2000;342:1334-49.

2. Gattinoni L, Pesenti A. The concept of "baby lung". Intensive Care Med. 2005;31:776-84.

3. Gattinoni L, Taccone P, Carlesso E, Marini JJ. Prone position in acute respiratory distress syndrome. Rationale, indications, and limits. Am J Respir Crit Care Med. 2013:188:1286-93.

4. Pelosi P, Tubiolo D, Mascheroni D, Vicardi P, Crotti S, Valenza F, Gattinoni L. Effects of the prone position on respiratory mechanics and gas exchange during acute lung injury. Am J Respir Crit Care Med. 1998;157:387-93.

5. Richard JC, Bregeon F, Costes N, Bars DL, Tourvieille C, Lavenne F, Janier M, Bourdin G, Gimenez G, Guerin C. Effects of prone position and positive end-expiratory pressure on lung perfusion and ventilation. Crit Care Med. 2008;36:2373-80.

6. Cornejo RA, Diaz JC, Tobar EA, Bruhn AR, Ramos CA, Gonzalez RA, Repetto CA, Romero CM, Galvez LR, Llanos O, Arellano DH, Neira WR, Diaz GA, Zamorano AJ, Pereira GL. Effects of prone positioning on lung protection in patients with acute respiratory distress syndrome. Am J Respir Crit Care Med. 2013;188:440-8
7. Santini A, Protti A, Langer T, Comini B, Monti M, Sparacino CC, Dondossola D, Gattinoni L. Prone position ameliorates lung elastance and increases functional residual capacity independently from lung recruitment. Intensive Care Med Exp. 2015;3:55.

8. Guerin C, Reignier J, Richard JC, Beuret P, Gacouin A, Boulain T, Mercier E, Badet M, Mercat A, Baudin O, Clavel M, Chatellier D, Jaber S, Rosselli S, Mancebo J, Sirodot M, Hilbert G, Bengler C, Richecoeur J, Gainnier M, Bayle F, Bourdin G, Leray V, Girard R, Baboi L, Ayzac L. Prone positioning in severe acute respiratory distress syndrome. N Engl J Med. 2013;368:2159-68.

9. Albert RK, Keniston A, Baboi L, Ayzac L, Guerin C. Prone position-induced improvement in gas exchange does not predict improved survival in the acute respiratory distress syndrome. Am J Respir Crit Care Med. 2014;189:494-6.

10. Guerin C, Baboi L, Richard JC. Mechanisms of the effects of prone positioning in acute respiratory distress syndrome. Intensive Care Med. 2014;40:1634-42.

11. Broccard A, Shapiro RS, Schmitz LL, Adams AB, Nahum A, Marini JJ. Prone positioning attenuates and redistributes ventilator-induced lung injury in dogs. Crit Care Med. 2000;28:295-303.

12. Valenza F, Guglielmi M, Maffioletti M, Tedesco C, Maccagni P, Fossali T, Aletti G, Porro GA, Irace M, Carlesso E, Carboni N, Lazzerini M, Gattinoni L. Prone position delays the progression of ventilator-induced lung injury in rats: does lung strain distribution play a role? Crit Care Med. 2005;33:361-7

13. Mutoh T, Guest RJ, Lamm WJ, Albert RK. Prone position alters the effect of volume overload on regional pleural pressures and improves hypoxemia in pigs in vivo. Am Rev Respir Dis. 1992;146:300-6.

14. Pelosi P, Bottino N, Chiumello D, Caironi P, Panigada M, Gamberoni C, Colombo G, Bigatello LM, Gattinoni L. Sigh in supine and prone position during acute respiratory distress syndrome. Am J Respir Crit Care Med. 2003;167:521-7.

15. Mentzelopoulos SD, Roussos C, Zakynthinos SG. Static pressure volume curves and body posture in acute respiratory failure. Intensive Care Med. 2005;31:1683-92.

16. Mentzelopoulos SD, Roussos C, Zakynthinos SG. Prone position reduces lung stress and strain in severe acute respiratory distress syndrome. Eur Respir J. 2005;25:534-44.

17. Reutershan J, Schmitt A, Dietz K, Unertl K, Fretschner R. Alveolar recruitment during prone position: time matters. Clin Sci (Lond). 2006;110:655-63

18. Chiumello D, Carlesso E, Cadringher P, Caironi P, Valenza F, Polli F, Tallarini F, Cozzi P, Cressoni M, Colombo A, Marini JJ, Gattinoni L. Lung stress and strain during mechanical ventilation for acute respiratory distress syndrome. Am J Respir Crit Care Med. 2008;178:346-55.

19. Jonson B, Richard JC, Straus C, Mancebo J, Lemaire F, Brochard L. Pressure-volume curves and compliance in acute lung injury: evidence of recruitment above the lower inflection point. Am J Respir Crit Care Med. 1999;159:1172-8.

20. Maggiore SM, Jonson B, Richard JC, Jaber S, Lemaire F, Brochard L. Alveolar derecruitment at decremental positive end-expiratory pressure levels in acute lung injury: comparison with the lower inflection point, oxygenation, and compliance. Am J Respir Crit Care Med. 2001;164:795-801.

21. Crotti S, Mascheroni D, Caironi P, Pelosi P, Ronzoni G, Mondino M, Marini IJ, Gattinoni L. Recruitment and derecruitment during acute respiratory failure: a clinical study. Am J Respir Crit Care Med. 2001;164:131-40.

22. Ranieri VM, Rubenfeld GD, Thompson BT, Ferguson ND, Caldwell E, Fan E, Camporota L, Slutsky AS. Acute respiratory distress syndrome: the Berlin Definition. JAMA. 2012;307:2526-33.

23. Ranieri VM, Giuliani R, Fiore T, Dambrosio M, Milic-Emili J. Volumepressure curve of the respiratory system predicts effects of PEEP in ARDS: "occlusion" versus "constant flow" technique. Am J Respir Crit Care Med. 1994;149:19-27.

24. Dellamonica J, Lerolle N, Sargentini C, Beduneau G, Di Marco F, Mercat A, Richard JC, Diehl JL, Mancebo J, Rouby JJ, Lu Q, Bernardin G, Brochard L. PEEP-induced changes in lung volume in acute respiratory distress syndrome. Two methods to estimate alveolar recruitment. Intensive Care Med. 2011;37:1595-604.

25. Richard JC, Brochard L, Vandelet P, Breton L, Maggiore SM, Jonson B, Clabault K, Leroy J, Bonmarchand G. Respective effects of end-expiratory 
and end-inspiratory pressures on alveolar recruitment in acute lung injury. Crit Care Med. 2003;31:89-92.

26. Olegard C, Sondergaard S, Houltz E, Lundin S, Stenqvist O. Estimation of functional residual capacity at the bedside using standard monitoring equipment: a modified nitrogen washout/washin technique requiring a small change of the inspired oxygen fraction. Anesth Analg. 2005;101:206-12.

27. Dellamonica J, Lerolle N, Sargentini C, Beduneau G, Di Marco F, Mercat A, Richard JC, Diehl JL, Mancebo J, Rouby JJ, Lu Q, Bernardin G, Brochard L. Accuracy and precision of end-expiratory lung-volume measurements by automated nitrogen washout/washin technique in patients with acute respiratory distress syndrome. Crit Care. 2011;15:R294.

28. Chatte G, Sab JM, Dubois JM, Sirodot M, Gaussorgues P, Robert D. Prone position in mechanically ventilated patients with severe acute respiratory failure. Am J Respir Crit Care Med. 1997;155:473-8.

29. Mancebo J, Fernandez R, Blanch L, Rialp G, Gordo F, Ferrer M, Rodriguez F, Garro P, Ricart P, Vallverdu I, Gich I, Castano J, Saura P, Dominguez G, Bonet A, Albert RK. A multicenter trial of prolonged prone ventilation in severe acute respiratory distress syndrome. Am J Respir Crit Care Med. 2006;173:1233-9.

30. Ibanez J, Raurich JM. Normal values of functional residual capacity in the sitting and supine positions. Intensive Care Med. 1982:8:173-7.

31. Amato MB, Meade MO, Slutsky AS, Brochard L, Costa EL, Schoenfeld DA, Stewart TE, Briel M, Talmor D, Mercat A, Richard JC, Carvalho CR, Brower RG. Driving pressure and survival in the acute respiratory distress syndrome. N Engl J Med. 2015;372:747-55.

32. Protti A, Cressoni M, Santini A, Langer T, Mietto C, Febres D, Chierichetti M, Coppola S, Conte G, Gatti S, Leopardi O, Masson S, Lombardi L, Lazzerini M, Rampoldi E, Cadringher P, Gattinoni L. Lung stress and strain during mechanical ventilation: any safe threshold? Am J Respir Crit Care Med. 2011;183:1354-62.

33. Protti A, Andreis DT, Monti M, Santini A, Sparacino CC, Langer T, Votta E, Gatti S, Lombardi L, Leopardi O, Masson S, Cressoni M, Gattinoni L. Lung stress and strain during mechanical ventilation: any difference between statics and dynamics? Crit Care Med. 2013;41:1046-55.

34. Galiatsou E, Kostanti E, Svarna E, Kitsakos A, Koulouras V, Efremidis SC, Nakos G. Prone position augments recruitment and prevents alveolar overinflation in acute lung injury. Am J Respir Crit Care Med. 2006;174:187-97.

35. Nieszkowska A, Lu Q, Vieira S, Elman M, Fetita C, Rouby JJ. Incidence and regional distribution of lung overinflation during mechanical ventilation with positive end-expiratory pressure. Crit Care Med. 2004;32:1496-503.
36. Chiumello D, Marino A, Brioni M, Cigada I, Menga F, Colombo A, Crimella F, Algieri I, Cressoni M, Carlesso E, Gattinoni L. Lung recruitment assessed by respiratory mechanics and computed tomography in patients with acute respiratory distress syndrome. What Is the relationship? Am J Respir Crit Care Med. 2016;193:1254-63.

37. Dreyfuss D, Saumon G. Ventilator-induced lung injury: lessons from experimental studies. Am J Respir Crit Care Med. 1998;157:294-323.

38. Gonzalez-Lopez A, Garcia-Prieto E, Batalla-Solis E, Amado-Rodriguez L, Avello N, Blanch L, Albaiceta GM. Lung strain and biological response in mechanically ventilated patients. Intensive Care Med. 2012;38:240-7.

39. Bellani G, Guerra L, Musch G, Zanella A, Patroniti N, Mauri T, Messa C, Pesenti A. Lung regional metabolic activity and gas volume changes induced by tidal ventilation in patients with acute lung injury. Am J Respir Crit Care Med. 2011;183:1193-9.

40. Guerin C, Beuret P, Constantin JM, Bellani G, Garcia-Olivares P, Roca O, Meertens JH, Maia PA, Becher T, Peterson J, Larsson A, Gurjar M, Hajjej Z, Kovari F, Assiri AH, Mainas E, Hasan MS, Morocho-Tutillo DR, Baboi L, Chretien JM, Francois G, Ayzac L, Chen L, Brochard L, Mercat A, investigators of the APRONET Study Group, the REVA Network, the Réseau recherche de la Société Française d'Anesthésie-Réanimation (SFAR-recherche), the ESICM Trials Group. A prospective international observational prevalence study on prone positioning of ARDS patients: the APRONET (ARDS Prone Position Network) study. Intensive Care Med. 2018;44:22-37. https://doi. org/10.1007/s00134-017-4996-5.

41. Grasso S, Mascia L, Del Turco M, Malacarne P, Giunta F, Brochard L, Slutsky AS, Marco Ranieri V. Effects of recruiting maneuvers in patients with acute respiratory distress syndrome ventilated with protective ventilatory strategy. Anesthesiology. 2002;96:795-802.

42. Gattinoni L, Caironi P, Cressoni M, Chiumello D, Ranieri VM, Quintel M, Russo S, Patroniti N, Cornejo R, Bugedo G. Lung recruitment in patients with the acute respiratory distress syndrome. N Engl J Med. 2006;354:1775-86.

43. Nakos G, Tsangaris I, Kostanti E, Nathanail C, Lachana A, Koulouras V, Kastani D. Effect of the prone position on patients with hydrostatic pulmonary edema compared with patients with acute respiratory distress syndrome and pulmonary fibrosis. Am J Respir Crit Care Med. 2000;161:360-8.

44. Cressoni M, Cadringher P, Chiurazzi C, Amini M, Gallazzi E, Marino A, Brioni M, Carlesso E, Chiumello D, Quintel M, Bugedo G, Gattinoni L. Lung inhomogeneity in patients with acute respiratory distress syndrome. Am J Respir Crit Care Med. 2014;189:149-58.

\section{Submit your manuscript to a SpringerOpen ${ }^{\odot}$ journal and benefit from:}

- Convenient online submission

- Rigorous peer review

- Open access: articles freely available online

- High visibility within the field

- Retaining the copyright to your article

Submit your next manuscript at $\boldsymbol{\nabla}$ springeropen.com 